18. Петрова Р.Г., Рябова Т.В. Восприятие инновационных образовательных технологий студентами младших курсов на примере медицинского вуза // Казанский пед. журнал. 2017. № 1 (120). С. 164-168.

19. Бойцова Е.А., Дроздов В.И. Модульно-рейтинговая система на базе тестовых технологий // Высшее образование в России. 2005. № 4. С. 83-85.

20. Дулова О.В., Цинкер В.М. Структурные и функциональные компоненты технологии реализа- ции модульно-компетентностного подхода // Вестник Бурятского государственного университета. 2010. № 13. C. 49-52.

21. Грузкова С.Ю., Камалеева А.Р., Левина Е.Ю. Реализация модульно-компетентностного подхода при проектировании учебных модулей естественнонаучных и профессиональных дисциплин // Инновации в образовании. 2016. № 3. С. 62-73.

\title{
INTEGRATIVE-MODULAR TECHNOLOGY OF GENERAL CHEMISTRY TEACHING
}

(C) 2018

Perederina Irina Alexandrovna, candidate of chemical sciences, associate professor of Chemistry Department

Tveryakova Elena Nikitichna, candidate of chemical sciences, associate professor of Chemistry Department Siberia State Medical University (Tomsk, Russian Federation)

Miroshnichenko Yuliya Yuryevna, candidate of chemical sciences, associate professor of General Chemistry and Chemical Technology Department National Research Tomsk Polytechnic University (Tomsk, Russian Federation)

Drygunova Larisa Alexandrovna, candidate of chemical sciences, associate professor of Chemistry Department Zykova Mariya Vladimirivna, candidate of pharmaceutical sciences, head of Chemistry Department

Zholobova Galina Alexandrovna, candidate of chemical sciences, associate professor of Chemistry Department Golubina Olga Alexandrovna, candidate of chemical sciences, associate Professor of Chemistry Department Siberia State Medical University (Tomsk, Russian Federation)

Abstract. The paper deals with integrative and modular technology of teaching General Chemistry to medical students that was developed and implemented at Chemistry Department of Siberian State Medical University. To design educational programs, the paradigm of training was exchanged to the paradigm of productive exercises with greater independence of students who become designers of their own knowledge, professional and universal competences. The content block of this discipline consists of two components: invariant and variant. Invariant component includes elective course on the chemistry of biologically active compounds. The paper describes the use of combination of academic and innovative methods and technologies of training. An approximate algorithm is offered for the course module, which focuses on the adsorption equilibrium and processes. It includes theoretical training, provided by textbooks, lecture text and teaching aids. Students assess the quality of academic work on their own with the help of tests and in the implementation of practical tasks in laboratory studies.

Keywords: integrative and modular training; invariant and variable components of training; elective course chemistry; medical profile; adsorption equilibrium and processes; related subjects; general chemistry; inorganic chemistry; educational technology; teaching methods; innovative teaching methods, innovative methods of learning; professional competence.

УДК 159.9

Статья поступила в редакцию 15.03.2017

\section{ИССЛЕДОВАНИЕ ВОЛЕВЫХ КАЧЕСТВ УЧАЩИХСЯ КАК ОДНОГО ИЗ АСПЕКТОВ ЛИЧНОСТНЫХ ДОСТИЖЕНИЙ В ФИЗКУЛЬТУРНО-СПОРТИВНОЙ ДЕЯТЕЛЬНОСТИ}

(C) 2018

Сафоненко Светлана Владимировна, кандидат педагогических наук, доцент кафедры спортивных дисциплин

Самарский государственный соииально-педагогический университет (2. Самара, Российская Федераиия)

Аннотация. В статье представлено исследование волевых качеств учащихся как одного из аспектов личностных достижений в физкультурно-спортивной деятельности; педагогических условий, обеспечивающих формирование различных волевых качеств, таких как целеустремленность, решительность и смелость, настойчивость, дисциплинированность, самообладание и выдержка, самостоятельность. Выявлены факторы, способствующие формированию волевого воспитания, воспитанию волевых качеств в процессе занятий физкультурно-спортивной деятельностью. В работе представлена разработанная и внедренная в процесс физического воспитания в условиях экспериментальной базы экспериментальная методика, направленная на формирование волевых качеств как одного из аспектов личностных достижений в физкультурно-спортивной деятельности. В основу данной экспериментальной методики формирования волевых качеств учащихся в физкультурно-спортивной деятельности легли различные педагогические приемы, обеспечивающие необходимость систематичного и постепенного преодоления объективных и субъективных трудностей во время выполнения предложенных заданий, при условии соблюдения определенных требований: возрастание сложности препятствий; согласованность величины трудности с возможностями занимающегося по ее преодолению; выполнение заданий в условиях преодоления состояния утомления; использование соревновательного метода обучения; усложнение внешних условий деятельности; формирование сознательной активности за- 
нимающихся в направлении развития собственных волевых качеств. Создание специально организованных педагогических условий позволило сформировать у учащихся необходимые волевые качества как один из аспектов личностных достижений в физкультурно-спортивной деятельности, повысить мотивацию к занятиям физкультурно-спортивной деятельностью, потребность в самореализации в физкультурно-спортивной деятельности, приобрести положительный опыт личностных достижений в физкультурно-спортивной деятельности.

Ключевые слова: личностные достижения; волевое воспитание; волевые качества; целеустремленность; решительность и смелость; настойчивость; дисциплинированность; самообладание и выдержка; самостоятельность; педагогические условия; факторы; мотивация; самореализация; воля; систематичность; преодоление трудностей.

В современных условиях развития правового государства и демократического общества в России школа становится важнейшим фактором гуманизации общественных отношений, формирования новых жизненных установок личности. На фоне общих процессов гуманизации и гуманитаризации, смены ценностных парадигм образования приоритетное развитие получают личностно-ориентированный и личностно-деятельностный подходы, отражающие субъект-субъектные аспекты педагогического взаимодействия. Выраженная потребность общества в адаптивной личности, обладающей потенциалом самореализации и самоактуализации, обусловливает необходимость создания образовательной среды, в которой каждый учащийся хотел бы, умел и любил учиться, совершенствуя себя. Особое внимание к индивидуальности человека, ориентация на его самосовершенствование - отличительная черта гуманистической парадигмы образования.

Образовательные учреждения, обладая значительным педагогическим потенциалом для формирования стремления учащихся к личностным достижениям, должны предоставлять учащимся право свободного выбора деятельности, уровня сложности и темпа освоения образовательной программы, создавать благоприятные условия, предоставляющие возможности любому ребенку «ощутить ни с чем не сравнимую радость первенства» $[1$, с. 4]. Результатом образовательной деятельности должна выступать успешность детей. При этом значимым критерием оценки результативности учебно-воспитательного процесса в образовательной системе должна рассматриваться динамика личностных достижений учащихся, одним из аспектов которых является волевое воспитание: формирование волевых качеств, необходимых для достижения результатов в учебной, а также в физкультурно-спортивной деятельности (ФСД).

В современном обществе давно назрела потребность в воспитании личности, способной к самореализации, самоактуализации, что становится возможным благодаря созданию особой образовательной среды, в которой необходимо организовать определенные условия для формирования индивидуальности обучающегося, создать потенциальные возможности для его самосовершенствования, развития волевых качеств. Создание таких условий обеспечивает и определяет актуальность нашего исследования. Реализация этой идеи в образовании предполагает ориентацию школы на личность каждого учащегося, на обеспечение его личностного роста и личностных достижений [2, с. 106].

Решение данной проблемы возможно при формировании стремления учащихся к личностным дости- жениям, что предполагает организацию специальных педагогических условий и преобразование роли педагога-инструктора в педагогическом процессе. Данное обстоятельство имеет большое значение при организации физкультурно-спортивной деятельности современных школьников в процессе занятий физической культурой и спортом. Анализ практики работы педагогов-тренеров позволил установить односторонность понимания ими сущности волевых качеств личности и путей их воспитания. Эти качества в большинстве случаев связываются лишь со спортивными личностными достижениями. По мнению Г.Д. Горбунова (2006) [3], К.П. Жарова (2006) [4] мало внимания уделяется гуманизации взаимоотношений, формам взаимодействия детей, способствующим формированию навыков коллективного сотрудничества и совместного преодоления трудностей, наконец, переживанию радости от успешно проделанной работы.

Такое сужение сферы проявления волевых качеств, недоценка воспитательных возможностей физкультурно-спортивной деятельности ограничивают эффективность целостного воспитательного процесса. Как утверждает Ю.И. Зотов [5], упущения в школьном и особенно в семейном воспитании порождают у некоторой части детей, преимущественно в подростковом возрасте, отрицательные черты характера, слабое волевое развитие. В то же время необходимые предпосылки для формирования волевых качеств у подростков имеются, так как ими уже накоплен достаточный опыт морального поведения, пробуждается нравственная потребность в жизненном самоопределении и самовоспитании.

Фактом является то, что интерес к занятиям физическими упражнениями проявляют многие подростки. Эмоциональное воздействие занятий при грамотной постановке учебно-тренировочной и воспитательной работы может оказать положительное влияние на формирование здоровой психики у учащихся, на эффективность развития у них волевых качеств, а следовательно, формирования стремления к личностным достижениям.

По мнению многих ученых, воспитание волевых качеств возможно лишь в процессе деятельности, когда эти качества необходимо проявить. Поэтому выполнение тех или иных заданий воспитательного характера на занятиях ФСД должно быть мотивированным. Действия занимающегося в условиях, где он проявляет волевые качества, могут быть наиболее полно реализованы только тогда, когда созданы обстоятельства положительной деятельности, основанной на стремлении к достижению цели. Ю.И. Зотов утверждает, что увлеченность положительной деятельностью является необходимым элементом для 
процесса развития волевых качеств, особенно в начальный период воспитательной работы с подростками [5, с. 11]. Здесь мотивация играет роль побуждения к действию. Она определяет базовую основу процесса сознательного преодоления трудностей.

Необходимо отметить, что эмоциональное удовлетворение, испытываемое подростками на занятиях ФСД, интерес к двигательной деятельности, а также целый ряд социальных мотивов являются основанием для формирования у них положительного отношения к данному виду деятельности.

Важным элементом формирования позитивного отношения занимающихся подросткового возраста к осуществлению воспитательного процесса на занятиях ФСД следует считать ликвидацию пробелов в волевом развитии. Тут особое значение имеет индивидуальный подход в обучении. Любой подросток, ощущая собственные недостатки при выполнении тех или иных физических упражнений, учитывая уровень физической и психологической нагрузки, может отказаться от продолжения занятий. Этот факт особенно ярко прослеживается в ситуациях, когда занимающийся работает в коллективе. Здесь социальный мотив - сохранение своего достоинства перед сверстниками - может подавить положительную мотивацию на достижение спортивного результата. Это, как правило, отрицательно сказывается на процессе развития волевых качеств. Тут могут развиваться негативные черты личности: конфликтность, грубость, неуверенность в своих силах, пассивность, отсутствие настойчивости, скрытность.

Мотивация к занятиям физическими упражнениями, ликвидация пробелов в волевом развитии являются компонентами подготовительного периода в организации развития волевых качеств подростка.

Практическое решение задач повышения уровня волевой подготовки учащихся определяет следующий этап развития волевых качеств. Здесь, в ходе воспитательного процесса, на первый план выходят проблемы организации методических, особых педагогических условий волевого развития на занятиях ФСД и контрольно-корректировочных мероприятий в формировании у подростков навыков самовоспитания [6]. Речь идет прежде всего о воспитании таких качеств, как: ФСД;

1) сознательное отношение к учебе и занятиям

2) ответственность за результаты деятельности;

3) способность регулировать свое поведение, считаться с общественными правилами и нормами занятий ФСД.

Управление процессом развития волевых качеств подростков на занятиях ФСД согласуется с необходимостью характеристики тех качеств личности, которые наиболее востребованы физкультурно-спортивной деятельностью и могут проявляться за счет особенностей выполнения двигательной работы, действий, направленных на достижение спортивного результата.

Общие результаты исследований К.П. Жарова [4], Ю.И. Зотова [5], К.Н. Корнилова [7], А.А. Лапаяна [7], В.М. Мельникова [8] и др. показывают, что одним из важнейших волевых качеств, проявляющихся и развивающихся за счет выполнения физкультурно- спортивной деятельности, является целеустремленность. Она характеризуется как способность длительного и планомерного выполнения принятых решений и доведения начатых дел до конца. Целеустремленный человек всегда подчиняет свою деятельность главной цели. В спорте эта цель связана с достижением результата. Целеустремленный спортсмен отличается волевым упорством, неуклонным стремлением к выполнению намеченных задач. Одним из показателей целеустремленности является способность ставить реальные цели, а при их достижении намечать новые, еще более сложные и трудные.

По данным Р.3. Шайхтдинова [9], подавляющее большинство спортсменов и тренеров считают, что без целеустремленности невозможно достичь высоких спортивных результатов. Его исследования показывают, что целеустремленность является основополагающим волевым качеством, от развития которого зависит проявление в полной мере других качеств воли. Целеустремленность определяет уверенность спортсмена в своих действиях, что, как утверждают психологи спорта, значительно повышает эффективность рабочих движений [9, с. 13].

Не менее важным волевым качеством является самостоятельность. В.В. Медведев [10] определяет это качество как способность спортсмена подчинять поведение собственным взглядам или убеждением. Самостоятельный человек не поддается попыткам склонить его к действиям, противоречащим его принципам. Однако это не значит, что спортсмен отвергает чужое мнение. Он готов всегда рассмотреть советы и указания тренера или партнера, оценить их и, если они разумные и актуальные, принять их. Отвержение же всякого чужого мнения по причинам, что оно неприемлемо для спортсмена в достижении намеченных целей, является показателем отрицательного качества личности - негативизма [11, с. 102]. Негативист не обладает самостоятельностью воли. Стремясь во что бы то ни стало действовать наперекор, он зачастую поступает вопреки собственным взглядам и убеждениям.

Как показывают исследования Ю.И. Зотова, К.П. Жарова и др., самостоятельный спортсмен легче переносит любые неудачи, с большим усердием преодолевает трудности в деятельности.

Решительность - это еще одно важное качество в физкультурно-спортивной деятельности, которое характеризуется как способность своевременно принимать устойчивые решения, без задержки переходить к их осуществлению $[12$, с. 420$]$. К понятию решительности относится и представление об обратном действии: быстро задержать или вообще прекратить выполнение принятого решения, если этого требуют данные обстоятельства. Особенно ярко это волевое качество проявляется в ситуациях, связанных с риском. Нерешительный человек не уверен в правильности своего решения, постоянно пересматривает, отменяет его.

Причинами такого поведения в физкультурноспортивной деятельности могут быть различные обстоятельства: боязнь возникновения неожиданных препятствий, потеря веры в свои силы, переживание прошлых неудач, перенесенных травм и т.п. [11; 12]. 
Иногда нерешительность - это следствие недостаточной опытности занимающегося.

Настойчивость тоже является ведущим волевым качеством занимающегося. Она способна заставить человека доводить начатое дело до конца, преодолевая препятствия и трудности на пути к цели [13, c. 34]. При неудачах настойчивый человек не падает духом. Наоборот, он проникается еще более твердой решительностью добиваться намеченного. Он ищет для этого новые пути и средства. Как указывает В.М. Мельников, от настойчивости следует отличать отрицательные качества воли - упрямство [8, с. 112]. Это качество лишь прикрывает слабоволие, так как упрямый человек не в силах побороть себя, отказаться от действий, ошибочность которых понимает сам.

Настойчивость позволяет спортсмену мобилизовать свои силы в ответственные периоды своей деятельности.

Выдержка (самообладание) - это способность постоянно контролировать свое поведение, воздерживаться от действий, которые осознаются человеком как ненужные или вредные в данных условиях деятельности. Это возможность человека сохранять хладнокровие даже в трудных обстоятельствах [12, с. 421].

Выдержанный человек вынослив и терпелив. Он способен, в случае необходимости стойко переносить лишения и боль. Существует противоположное качество - импульсивность. Такой спортсмен склонен действовать по первому побуждению, поспешно, не обдумывая своих поступков и их последствий.

Выдержка нужна спортсмену для успешного управления своими эмоциями в ситуациях временных ошибок, преодоления трудностей в соревновательных условиях $[13 ; 14]$.

Смелость - это готовность к опасности, к преодолению невзгод, страданий и лишений [12, с. 420]. А.В. Родионов [12] подчеркивает, что это волевое качество определяется готовностью спортсмена выполнять опасные действия. Противоположное качество - трусость. Страх за себя и свое благополучие руководит действиями трусливого человека. Он способен даже изменить своему долгу [15]. Физкультурно-спортивная деятельность полна ситуаций, где смелость может не только проявляться, но и иметь решающее значение для достижения успеха.

Человек, желающий добиться высоких результатов в физкультурно-спортивной деятельности, должен обладать и таким волевым качеством личности, как дисциплинированность. Это качество определяется психологами спорта как сознательное подчинение своего поведения общественным правилам и нормам $[16 ; 17]$.

Дисциплина проявляется в том, что спортсмен без принуждения признает для себя обязательным выполнять нормы, которые от него требуют окружающие люди и законы спорта. Известно, что соблюдение общественных правил, выполнение распоряжений, значимых для достижения поставленных целей, развивают волю человека, учат его преодолевать препятствия и трудности. Спортсмен становится способным действовать не только «потому, что хочется», но и ради того, что «надо».

Проявление воли зависит от мотива деятельности и от того, насколько он совпадает с жизненными ин- тересами человека. Вместе с тем во внешнем выражении волевые качества не могут проявляться помимо мышечных движений. Этим обусловлено единство физического и волевого воспитания, в процессе обучения движениям, воспитания физических способностей и особенно в процессе спортивного совершенствования обязательно приводятся в действие, проявляются и развиваются волевые свойства личности [18]. Не случайно современное определение воли согласуется с тем, что это сознательная саморегуляция человеком своей деятельности, обеспечивающая преодоление препятствие и трудностей на пути к цели [3].

В литературе по проблемам воспитания волевых качеств в физкультурно-спортивной деятельности основные задачи обеспечения этого процесса состоят в том, чтобы:

- формировать мотивационные, интеллектуальные и нравственные основы волевых проявлений;

- разносторонне развивать волевые качества, необходимые в деятельности, формировать на этой основе черты характера, которые позитивно раскрывают возможности человека в жизнедеятельности [19].

Специфическим фактором воспитания волевых качеств является преодоление трудностей, которые связаны с мобилизацией сил. В физкультурно-спортивной деятельности выделяют ряд необходимых условий для реализации воспитательного процесса в этом направлении. К ним относят:

а) систематическое преодоление трудностей;

б) возрастание сложностей препятствий;

в) возрастание не исключает возможностей их преодоления [20, с. 54].

Введение заданий и установок на развитие волевых качеств связано с рядом требований:

1) осуществление процесса развития воли возможно только тогда, когда достигается устойчивая адаптация к относительно стандартным комплексам физических упражнений;

2) возможность определения специальной установки на проявление волевых качеств согласуется с приспособлением организма человека к определенному уровню физической и психологической нагрузки;

3) важно, чтобы разученные упражнения были уже привычными для занимающегося и не требовали сами по себе значительных волевых усилий [16, c. 47].

Для этого в современной системе физического воспитания и спорта рекомендуется использовать ряд специальных приемов:

- введение заданий по превышению привычных параметров усилий (преодоление утомления);

- введение соревновательных начал с установкой на обязательное достижение заданного результата;

- стимулирование волевых проявлений путем усложнений внешних условий деятельности [20, c. 50].

В.В. Кузин [20], А.Т. Паршиков [20], М.Я. Виленский [20] указывают, что эффективность воспитания волевых качеств в конечном счете определяется тем, насколько этот процесс перерастает сознательную активность занимающегося, направленную на выработку своих волевых качеств. 
Таким образом:

1. Выполнение физических упражнений связано с развитием волевых качеств человека.

2. Важнейшим условием развития воли на занятиях ФСД является постановка задач на воспитание волевых качеств, учитывая нравственное воздействие и активное содействие самого занимающегося в развитии его воли.

3. Процесс воспитания волевых качеств определяется этапностью задач деятельности: 1) формирование позитивного отношения занимающихся подросткового возраста к осуществлению собственного волевого развития; 2) ликвидация пробелов в развитии волевых качеств; 3) повышение уровня волевой подготовки.

4. К наиболее значимым в физкультурно-спортивной деятельности волевым качествам следует отнести: целеустремленность, самостоятельность, решительность, настойчивость, выдержка (самообладание), смелость, дисциплинированность.

5. Реализация воспитания воли у занимающихся на занятиях ФСД должна опираться на ряд требований:

a) систематичность преодоления трудностей;

б) возрастание сложности препятствий;

в) согласованность величины трудности с возможностями занимающегося по ее преодолению;

г) выполнение заданий в условиях преодоления состояния утомления;

д) использование соревновательного метода обучения;

е) усложнение внешних условий деятельности;

ж) формирование сознательной активности занимающихся в направлении развития собственных волевых качеств.

Исходя из анализа научно-исследовательской литературы, нами была сформулирована проблема исследования, которая определяется поиском ответа на вопрос: какие необходимы методические и педагогические условия для повышения эффективности развития волевых качеств как одного из аспектов личностных достижений у подростков в ФСД.

В процессе развития волевых качеств в экспериментальной группе нами были введены задания, обеспечивающие необходимость систематичного и постепенного преодоления объективных и субъективных трудностей.

Определение волевых качеств личности по методике И.П. Волкова [21] определяет конкретные особенностей волевых проявлений: самообладание, настойчивость, решительность, умение мобилизовать резервы. В предложенной экспериментальной методике осуществлялось развитие отдельных волевых качеств:

- целеустремленность - упражнения по формированию умения определять цели, ставить задачи и их ранжировать, определять этапы работы при выполнении заданий;

- самостоятельность и инициативность - задания, требующие умения действовать нестандартно, самостоятельно находить решение, видеть различные варианты достижения цели, критично относиться к советам, избегать копирования действий. Включали организацию проблемных ситуаций, усложнение условий выполнения заданий, организацию соревновательных ситуаций;
- решительность и смелость - упражнения, направленные на обучение способам поиска целесообразных действий в различных усложненных условиях, развитие уверенности в принятии решения;

- настойчивость и упорство - условия моделирования проигрыша, выполнение заданий соревновательным методом с более сильным соперником, требующие проявления способности активно преодолевать трудности, сопротивляться снижению активности при неудачах, ошибках, неожиданных трудностях;

- выдержка и самообладание - обучение методам психической саморегуляции (самоприказы, самоубеждения).

Основу волевого воспитания подростков экспериментальной группы составляли такие методические приемы, как:

1) преодоление трудностей;

2) возрастание сложности препятствий;

3) преодоление состояния негативных состояний (утомления);

4) соревновательный метод обучения.

Главным методом волевого воспитания является систематические упражнения.

Следовательно, можно считать, что введение в учебно-воспитательный процесс специальных методов, направленных на волевое развитие подростков, является эффективным.

Этот факт подтверждается изменениями показателей самооценки волевых качеств испытуемых в период эксперимента.

Как показывают результаты исследования самооценки уровня развития волевых качеств в период эксперимента у занимающихся контрольной и экспериментальной группы, внедрение методики, направленной на воспитание волевых качеств на занятиях фитнесом, является эффективным.

Прирост показателей всех волевых качеств в экспериментальной группе явился достоверным на уровне не ниже $\mathrm{p}<0,05$ (табл. 1), в то время как в контрольной группе наблюдалась другая динамика прирост уровня волевых качеств оказался незначительным и недостоверным, а в ряде случаев имел отрицательную динамику (табл. 2).

Объективные сведения об уровне развития отдельных волевых качеств, полученные путем внедрения психофункциональных тестов, показали в контрольной группе следующие средние результаты:

1) степ-тест - индекс 107,1 балла;

2) 6-минутный бег - 1100 метров.

По шкале оценки индекса степ-теста указанное значение определяется удовлетворительным уровнем функциональных возможностей. Результат 6-минутного бега характеризуется также удовлетворительной оценкой. Согласно полученным данным, в начале эксперимента занимающиеся контрольной группы обладали средним уровнем развития настойчивости.

Занимающиеся экспериментальной группы по исходным данным имели:

1) степ-тест - индекс 108,2 балла;

2) 6-минутный бег - 1080 метров.

Оценка индекса степ-теста - удовлетворительная. Результат бега - низкий, близко к удовлетворительному. Можно считать, что занимающиеся экспериментальной группы в начале исследования показали средний уровень развития настойчивости. Однако, 
если сравнивать значения испытаний с показателями контрольной группы, то очевидным является факт более низкого уровня проявления настойчивости.

За период эксперимента наблюдались следующие изменения показателей настойчивости:

1) контрольная группа:

- степ-тест - увеличение индекса в среднем на 4 балла $(\mathrm{p}>0,05)$;

- 6-минутный бег - снижение результата в среднем на 10 метров (p>0,05).

Таблица 1 - Результаты исследования самооценки волевых умений в экспериментальной группе в период эксперимента, в баллах

\begin{tabular}{|c|c|c|c|c|c|c|}
\hline \multirow[b]{2}{*}{$\begin{array}{l}\text { Волевые } \\
\text { качества }\end{array}$} & \multirow[b]{2}{*}{ Волевые умения } & \multicolumn{5}{|c|}{ Оценка признаков волевых умений } \\
\hline & & До & $\begin{array}{l}\text { По- } \\
\text { сле }\end{array}$ & $\begin{array}{l}\text { Раз- } \\
\text { ница }\end{array}$ & $\begin{array}{l}\text { t-критерий } \\
\text { Стьюдента }\end{array}$ & $\mathrm{p}<$ \\
\hline \multirow{3}{*}{$\begin{array}{l}\text { Целе- } \\
\text { устремлен- } \\
\text { ность }\end{array}$} & 1. Ставить ясные цели и задачи & 2,2 & 4,8 & 2,6 & 2,057 & 0,05 \\
\hline & 2. Планомерно осуществлять деятельность & 3,3 & 5,7 & 2,4 & 2,054 & 0,05 \\
\hline & 3. Подчинять себя достижению поставленной цели & 1,6 & 4,6 & 3,0 & 2,067 & 0,05 \\
\hline \multirow{3}{*}{$\begin{array}{l}\text { Настойчи- } \\
\text { вость и } \\
\text { упорство }\end{array}$} & 4. Длительно добиваться намеченной цели & 3,4 & 6,0 & 2,6 & 2,048 & 0,05 \\
\hline & 5. Преодолевать тягостные состояния & 4,0 & 6,0 & 2,0 & 2,043 & 0,05 \\
\hline & 6. Продолжать деятельность несмотря на неудачи & 1,1 & 5,6 & 4,5 & 2,058 & 0,05 \\
\hline \multirow{3}{*}{$\begin{array}{l}\text { Решитель- } \\
\text { ность и } \\
\text { смелость }\end{array}$} & 7. Своевременно принимать ответственные решения & 2,6 & 4,8 & 2,2 & 2,069 & 0,05 \\
\hline & 8. Подавлять чувство страха & 4,4 & 5,9 & 1,5 & 2,056 & 0,05 \\
\hline & 9. Безотказно выполнять принятые решения & 3,6 & 6,0 & 2,4 & 2,065 & 0,05 \\
\hline \multirow{3}{*}{$\begin{array}{l}\text { Выдержка и } \\
\text { самообла- } \\
\text { дание } \\
\end{array}$} & 10. Сохранять ясность мысли & 2,2 & 5,3 & 3,1 & 2,069 & 0,05 \\
\hline & 11. Владеть своими чувствами & 4,4 & 5,8 & 1,4 & 2,042 & 0,05 \\
\hline & 12. Управлять своими действиями & 3,2 & 5,8 & 2,6 & 2,054 & 0,05 \\
\hline \multirow{3}{*}{$\begin{array}{l}\text { Самостоя- } \\
\text { тельность и } \\
\text { инициатив- } \\
\text { ность }\end{array}$} & 13. Проявлять независимость в решениях и действиях & 3,8 & 6,0 & 2,2 & 2,047 & 0,05 \\
\hline & 14. Проявлять личное творчество и новаторство & 3,8 & 5,6 & 1,8 & 2,045 & 0,05 \\
\hline & 15. Проявлять находчивость и сообразительность & 4,2 & 6,0 & 1,8 & 2,044 & 0,05 \\
\hline
\end{tabular}

Следовательно, в контрольной группе наблюдалось незначительное снижение уровня проявления настойчивости при выполнении физических упражнений. Очевидно снижение результативности в беге (не у всех занимающихся, т.к. $\mathrm{p}>0,05$ ).

2) экспериментальная группа:

- степ-тест - увеличение индекса в среднем на 10,2 балла $(\mathrm{p}<0,05)$;

-6-минутный бег - увеличение результата в среднем на 140 метров $(\mathrm{p}<0,05)$.

Таблица 2 - Результаты исследования самооценки волевых умений в контрольной группе в период эксперимента, в баллах

\begin{tabular}{|c|c|c|c|c|c|c|}
\hline \multirow{2}{*}{$\begin{array}{c}\text { Волевые ка- } \\
\text { чества }\end{array}$} & \multirow[b]{2}{*}{ Волевые умения } & \multicolumn{5}{|c|}{ Оценка признаков волевых умений } \\
\hline & & До & $\begin{array}{l}\text { По- } \\
\text { сле }\end{array}$ & $\begin{array}{l}\text { Раз- } \\
\text { ница }\end{array}$ & $\begin{array}{l}\text { t-критерий } \\
\text { Стьюдента }\end{array}$ & $\mathrm{p}<$ \\
\hline \multirow{3}{*}{$\begin{array}{l}\text { Целе- } \\
\text { устремлен- } \\
\text { ность }\end{array}$} & 1. Ставить ясные цели и задачи & 2,2 & 2,9 & 0,7 & 2,047 & 0,05 \\
\hline & 2. Планомерно осуществлять деятельность & 3,1 & 3,7 & 0,6 & 2,041 & - \\
\hline & 3. Подчинять себя достижению поставленной цели & 2,6 & 2,4 & $-0,2$ & 2,020 & - \\
\hline \multirow{3}{*}{$\begin{array}{l}\text { Настойчи- } \\
\text { вость и } \\
\text { упорство }\end{array}$} & 4. Длительно добиваться намеченной цели & 3,1 & 3,6 & 0,5 & 2,025 & - \\
\hline & 5. Преодолевать тягостные состояния & 4,3 & 3,8 & $-0,5$ & 2,013 & - \\
\hline & 6. Продолжать деятельность, несмотря на неудачи & 2,2 & 2,8 & 0,6 & 2,038 & - \\
\hline \multirow{3}{*}{$\begin{array}{l}\text { Решитель- } \\
\text { ность и } \\
\text { смелость }\end{array}$} & 7. Своевременно принимать ответственные решения & 2,0 & 3,6 & 1,6 & 2,049 & 0,05 \\
\hline & 8. Подавлять чувство страха & 3,4 & 3,8 & 0,4 & 2,036 & - \\
\hline & 9. Безотказно выполнять принятые решения & 1,8 & 1,9 & 0,1 & 2,039 & - \\
\hline \multirow{3}{*}{$\begin{array}{l}\text { Выдержка и } \\
\text { самообла- } \\
\text { дание }\end{array}$} & 10. Сохранять ясность мысли & 1,6 & 1,6 & 0 & 2,010 & - \\
\hline & 11. Владеть своими чувствами & 3,2 & 3,0 & $-0,2$ & 2,012 & - \\
\hline & 12. Управлять своими действиями & 2,8 & 2,7 & $-0,1$ & 2,007 & - \\
\hline \multirow{3}{*}{$\begin{array}{l}\text { Самостоя- } \\
\text { тельность и } \\
\text { инициатив- } \\
\text { ность }\end{array}$} & 13. Проявлять независимость в решениях и действиях & 2,3 & 2,5 & 0,2 & 2,017 & - \\
\hline & 14. Проявлять личное творчество и новаторство & 4,3 & 4,4 & 0,1 & 1,045 & - \\
\hline & 15. Проявлять находчивость и сообразительность & 4,2 & 4,9 & 0,7 & 2,037 & - \\
\hline
\end{tabular}

По данным экспериментальной группы, уровень проявления настойчивости при выполнении физических упражнений повысился с достаточным уровнем достоверности $(\mathrm{p}<0,05)$ по всем изучаемым показателям.

Оценка смелости проводилась с помощью испытания занимающихся при выполнении координационного упражнения на буме высотой 1,5 метра. При этом уровень проявления смелости у испытуемых контрольной группы был равен 2,8 балла, а экспериментальной группы - 2,4 балла.

По шкале оценок смелости при выполнении упражнения в обоих случаях отмечен низкий уровень проявления изучаемого качества. Более низкий уровень был показан учащимися экспериментальной группы. 
Сравнивая исходные и итоговые данные оценки смелости занимающихся контрольной группы, следует отметить, что уровень прироста показателей составил в среднем 0,2 ( $p>0,05)$ балла при отсутствии достоверности значений.

Изменение показателей у испытуемых экспериментальной группы отмечались достоверным приростом в среднем на $1,7(\mathrm{p}<0,05)$ балла.

Следовательно, уровень проявления смелости при выполнении физического упражнения на буме занимающимися контрольной группы за годичный период повысился с низкого до ниже среднего по шкале оценок. Уровень же показателей экспериментальной группы в конце эксперимента определялся как средний.

Таким образом, следует отметить, что экспериментальная методика, использованная в подготовке занимающихся экспериментальной группы, за период исследования дала значимый прирост в развитии смелости. Стоит отметить, что действия большинства подростков при выполнении сложного гимнастического упражнения на буме высотой 1,5 метра отличались решительностью, целеустремленностью. Учащиеся экспериментальной группы при подготовке к выполнению упражнения на оценку показывали настойчивость и целеустремленность.

Опираясь на анализ исходных и итоговых данных, а также обобщая полученные сведения, можно констатировать следующие результаты экспериментальной проверки эффективности экспериментальной методики:

1) целенаправленное воспитание волевых качеств у занимающихся 13-14-летнего возраста оказывает положительное влияние на развитие у подростков позитивного отношения к занятиям физкультурноспортивной деятельностью, и волевой подготовки к жизнедеятельности;

2) включение методических приемов развития волевых качеств у подростков в учебно-воспитательном процессе характеризуется приростом показателей уровня волевой подготовленности занимающихся среднего звена;

3) экспериментальная методика определяет развитие настойчивости волевого качества. По показателям функциональных возможностей в среднем на 10,2 ( $<$ < 0,05) балла, по данным изучения выносливости в среднем на 140 ( $<<0,05)$ метров;

4) введение методики волевого воспитания характеризуется повышением уровня развития смелости в среднем на 1,7 ( $<<0,05)$ балла за годичный период подготовки подростков.

В ходе экспериментальной проверки предлагаемой методики волевого воспитания подростков на занятиях ФСД нами был выделен ряд рекомендаций, которые необходимо учитывать при практическом использовании средств волевого развития в учебновоспитательном процессе. К ним относятся:

- строгое соблюдение этапов подготовки: 1) формирование позитивного отношения занимающихся к собственному волевому развитию; 2) учет и ликвидация пробелов в развитии отдельных волевых качеств; 3) повышение общего уровня волевой подготовки.

- построение воспитательного процесса должно опираться на принципы: 1) оптимальной трудности заданий; 2) сознательности; 3) связи с практической жизнью; 4) индивидуализации.

- необходимо единство средств волевого развития и спорта через интеграцию методов обучения: упражнение, приучение, преодоление препятствий, самостоятельная работа занимающихся.

- на формирование позитивного отношения подростка к собственному волевому развитию значительное активизирующее влияние оказывает способ демонстрации достижений, а также авторитетного примера.

- эффективность воспитательного воздействия повышается, если в учебно-воспитательном процессе на занятиях ФСД широко используются методы проблемного обучения, а занимающиеся свободно могут проявлять инициативу, творчество в решении тренировочных задач.

Комплексный анализ экспериментальных данных позволяет нам прийти к выводу, что у учащихся экспериментальной группы произошли позитивные изменения уровня волевых качеств как одного из аспектов личностных достижений, в сравнении с контрольной группой, что позволяет говорить об успешности внедрения экспериментальной методики по формированию волевых качеств в процессе занятий физкультурно-спортивной деятельностью.

Таким образом, полученные в ходе педагогического эксперимента данные указывают на эффективность разработанной нами экспериментальной методики и подтверждают выдвинутую нами гипотезу исследования.

\section{Список литературы:}

1. Сафоненко С.В. Формирование стремления учащихся к личностным достижениям в физкультурно-спортивной деятельности: дис. ... канд. пед. наук. Самара, 2006. 196 c.

2. Сафоненко С.В. Исследование процесса формирования стремления к личностным достижениям учащихся в физкультурно-спортивной деятельности // Самарский научный вестник. 2014. № 2 (7). С. 106109.

3. Горбунов Г.Д. Психопедагогика спорта. М.: Советский спорт, 2006. 296 с.

4. Жаров К.П. Волевая подготовка спортсмена. М.: ФиС, 2006. 151 с.

5. Зотов Ю.И. Воспитание подростков в спортивном коллективе. М., 2004. 102 с.

6. Гогунов Е.Н., Мартьянов Б.И. Психология физического воспитания и спорта. М.: Изд. центр «Академия», 2012. 288 с.

7. Корнилов К.Н., Лапаян А.А. Волевые усилия и значение трудностей в формировании воли. М.: ФиС, 1994. 157 c.

8. Мельников В.М. Психология. М.: ФиС, 2007. $367 \mathrm{c}$.

9. Шайхтдинов Р.3. Личность и волевая готовность в спорте. М.: ФиС, 2007. 112 с.

10. Медведев В.В. Волевая подготовка как составная часть психологической подготовки спортсмена. М., 2008. 296 c.

11. Ильин Е.П. Психофизиология физического воспитания. М.: Просвещение, 2010. 199 с.

12. Родионов А.В. Психология физического воспитания и спорта. М.: Академический проект, 2004. $576 \mathrm{c}$. 
13. Матвеев Л.П. Основы спортивной тренировки. М.: ФиС, 2007. 288 c.

14. Кочетов А.И. Педагогические основы самовоспитания. М., 2004. 234 с.

15. Кулагина И.Ю. Возрастная психология (развитие ребенка от рождения до 17 лет). М.: Изд. УРAO, 2007. $176 \mathrm{c}$.

16. Филин В.П. Теория и методика юношеского спорта. М.: ФиС, 2012. 129 с.

17. Методики психодиагностики в спорте / В.Л. Марищук, Ю.М. Блудов, В.А. Плахтиенко, Л.К. Серова. М.: Просвещение, 2010. 256 с.
18. Эмоционально-волевая подготовка спортсменов / под ред. А.Т. Филатова. К.: Здоровье, 2002. $295 \mathrm{c}$.

19. Тер-Ованесян А.А. Педагогические основы физического воспитания. М.: ФиС, 2008. 206 с.

20. Физическая культура / под общ. ред. А.Т. Паршикова, В.В. Кузина, М.Я. Виленского. М.: Спорт АкадемПресс, 2003. 174 с.

21. Практикум по спортивной психологии / под ред. И.П. Волкова. СПб.: Питер, 2002. 288 с.

\title{
STUDY OF STUDENTS' VOLITIONAL QUALITIES AS ONE OF THE ASPECTS OF PERSONAL ACHIEVEMENTS IN PHYSICAL CULTURE AND SPORTS ACTIVITIES
}

(C) 2018

\author{
Safonenko Svetlana Vladimirovna, candidate of pedagogical sciences, \\ associate professor of Sports Disciplines Department \\ Samara State University of Social Sciences and Education (Samara, Russian Federation)
}

Abstract. The paper presents a study of strong-willed qualities of students, as one of the aspects of personal achievements in physical culture and sports as well as pedagogical conditions that develop various volitional qualities: purposefulness, determination and courage, perseverance, discipline, self-control and independence. The author reveals factors that contribute to strong-willed education in the process of physical culture and sports activities. The paper describes the experimental technique developed and introduced into the process of physical education, aimed at strong-willed qualities development. The basis of the experimental methodology for students' strong-willed qualities development in sports and sports activities are various pedagogical methods that ensure the need for a systematic and gradual overcoming of objective and subjective difficulties while solving proposed tasks. They work under certain requirements: the increasing complexity of obstacles; the consistency of the magnitude of the difficulty with the capabilities of the practitioner in overcoming it; fulfillment of tasks in conditions of overcoming the state of fatigue; use of competitive method of training; complication of external conditions of activity; conscious activity development. Creating specially organized pedagogical conditions made it possible to develop students' necessary volitional qualities, to increase motivation to engage in physical culture and sports activities, to acquire a positive experience of personal achievements in physical culture activities.

Keywords: personal achievements; strong-willed education; strong-willed qualities; purposefulness; determination and courage; perseverance; discipline; self-control and self-control; independence; pedagogical conditions; factors; motivation; self-realization; will; systematic; overcoming difficulties.

УДК 378.046 .4

Статья поступила в редакцию 06.12.2017

\section{НАУЧНО-МЕТОДИЧЕСКОЕ ОБЕСПЕЧЕНИЕ ПОДГОТОВКИ ПРЕПОДАВАТЕЛЕЙ ВНУТРИФИРМЕННОГО ОБУЧЕНИЯ}

\author{
Хацринова Ольга Юрьевна, кандидат технических наук, \\ доцент кафедры инженерной педагогики и психологии \\ Казанский национальный исследовательский технологический университет \\ (2. Казань, Российская Федерачия)
}

\begin{abstract}
Аннотация. В данной статье рассматриваются вопросы повышения квалификации специалистов промышленности. Раскрываются проблемы реализации дополнительных образовательных программ подготовки инженерных кадров. Показаны условия построения внутрифирменного обучения слушателей системы дополнительного профессионального образования на основе достижений инженерной педагогики. Для реализации программы выбраны следующие методологические подходы: компетентностный, акмеологический и андрагогический. Использование этих подходов обеспечивает ориентацию на прогрессивное профессиональное развитие и саморазвитие, творческую самореализацию в профессиональной сфере и учитывает индивидуальный опыт каждого слушателя. Профессиональными стандартами определены компетенции, которые в процессе обучения должны получить свое развитие. Показано, что в процессе дополнительного профессионального образования формируемые компетенции носят интегративный характер, т.е. они должны объединять все результаты обучения. Содержание компетенций включает в себя не только традиционные результаты образования - знания, умения, навыки, но и личностные компоненты, такие как готовность человека на основе ранее полученного опыта и знаний решать профессиональные задачи нового уровня сложности, мобилизуя при этом все внутренние и внешние ресурсы. Показаны возможности реализации программы «Педагогическое мастерство преподавателя внутрифирменного обучения». Определено, что для осуществления процесса подготовки персонала преподавателю необходимо сформировать методическую компетентность. Разработаны индикаторы оценки методической компетентности преподавателей.
\end{abstract}

